\title{
On the Structural Adjustment of University in the Context of Hard Employment Recruitment ---And Some Discussion on Higher Vocational Training Mode
}

\author{
Guo Ying ${ }^{1,}$; Song Tingshan²,b, \\ School of Economics, Qilu Normal University, Jinan City, Shandong Province) \\ axiaoying1210@sina.com, bqlnusts@163.com
}

Keywords: The practice teaching; Modern vocational education; Classification of colleges and universities; Applied talents; Training mode

\begin{abstract}
Not all colleges and universities for elite education mode; Employment employment dilemma, have prompted us to thinking about the classification of Education; Set up a complete modern vocational education system, come up with a modern occupation education system standards and evaluation methods, given the policy inclination, lead level in vocational colleges, the existing three colleges and universities and a considerable part of two colleges and universities to occupation colleges; For the specialized subject of ordinary universities and colleges of undergraduate course to higher vocational training, college students to actively implement the "2+1" training mode, the implementation of " $3+1$ " training mode of undergraduates.
\end{abstract}

\section{Theoretical Basis}

It's true that the ordinary colleges are facing the high stress of employment. For one thing, it is hard for students to apply a suitable job, for another, the employers are also in the plight of recruit workers, thus it has posed both of them in a dilemma. However, there are fierce competitions in some positions, such as civil servants, bankers, and state-owners enterprise staff. But, to our curiosity, what caused this two extreme phenomenon? We first analyze this problem from the following steps: If there is something wrong in our structure of universities? Are there existing some disparities in treats among different careers? Or, our education's patterns could not apply the development of society any more? And how can we turn around our present situations?

On $10^{\text {th }}$ January, 2012, The Ministry of Education as well as other 7 ministries together formed "several opinions on further strengthen the education through practice in colleges and universities", and pointed that: "we should focus more on the practical teaching program.......and every higher colleges are required to set the practical teaching standards correspondingly, to add more practical teaching in our teaching program, according to the profession's features and requirements for the cultivation of talents. We also should make sure an appropriate proportion in our teaching: as for the undergraduate majors, the humanities and social sciences is not less than $15 \%$ of the total credits(periods), the science and engineering, agriculture and medial professions not less than 50\%. For normal students ,the experience for teaching internship is at least one semester, and for MSPM is at least up to half years "; " deep the reform of practical teaching methods", "implement social practice activities methodically....he total time of social practice activities is at least up to 4 weeks for undergraduates, and postgraduates, for 2 weeks in their school days, every students are required ${ }^{1}$ to partake in social surveys at least one time, and better to write a survey report accordingly" ${ }^{11}$ 。

Our premier, Li Keqiang, presided the executive meeting of the State Council, on the 26 February, 2014,to deploy the plan s to accelerate development of modern vocational education and the measures." Firstly, we should keep the vocational education on the core position of our national talents cultivation system, to nurish a good social atmosphere - "encourage and respect the

\footnotetext{
${ }^{1}$ [fund project: Shandong Province vocational and adult education research: research approaches to training program specialist technical application type college sand Implementation (2013zcj003)]
}

[Author introduction: Guo Ying (1981 -), female, Shandong Tai'an, lecturer; Song Tingshan (1962 -), male, Shandong Haiyang , Professor, tutor. ] 
special skills and capabilities rather than educational background ",to encourage the young people to learn special professional skills"Secondly, we should create a pattern of vocational education,......form a system of accumulation of credits , and make it is more accessible to the postgraduate education for secondary vocational schools students, junior colleges students and undergraduates. And we should guide them to transfer from regular undergraduate colleges to technological application colleges....... ${ }^{\mathbf{2} \mathbf{1}}$.

\section{The Classification of Colleges}

At present, the recognitions of higher educational schools mainly depend on the government and the bureau of education, academic research institutions, as well as colleges themselves. Basically, we can divide them into 3 categories, that is, universities for research and teaching study, universities for 4 years' undergraduate education and colleges for professional education ${ }^{\mathbf{k} \mathbf{1}}$.

As what professor kong Fanmin from Peking Comprehensive University once introduced, China's higher education started in 1995 when a series of higher educational programs such as " 211 " and " 985 " sequentially carried out,among which are all the key programs that our nation is trying to cultivate .Generally, they are composed of universities who focus on research and some on teaching study, besides they are also our major goals of building world first-class universities and advanced-level colleges.Another part we are paying effort is the building of the higher professional or career-oriented education, which takes the responsibility to cultivate the technical intelligences that our nation desperately needs in the aspects of the social production, service,and management. What 's more, Between the two kinds are those general undergraduate universities which cultivate practical intelligences in research and teaching study. Seeing the biggest percentage of them, we have to make it clear about the position in the higher educational system ${ }^{\mathbf{4} \mathbf{1}}$.

The classification work of higher education in ShanDong Province will almost be done by November $5^{\text {th }}$, 2012, which means the former educational pattern "Rank education, Rank management" will transfer to the "Classification education,Classification management". ShanDong higher education has realized the historical leap from elite education to public education,and forwarding to the universal. At the meanwhile,the structure of higher educational schools should meet the needs of the diversity of the social human resources market ,and different universities should have the different divisions,education targets and criteria. By taking the advantages of building the advanced higher educational universities, ShanDong province should take the chance to enhance the classificational guidances, and divided universities into Fundamental Application-oriented,Application-oriented and Technique-oriented, so that we can make a good control of the classification management and construction, and then help them identify their distinguishing features forming their own educational ideas and styles.among those universities, Shandong Science and Technology University and other 4 universities have been identified as the first Application-oriented constructions, while Shandong Laber Vocational and Technical College, Laiwu Vocational and Technical College and other 11 higher educational schools become the first Technique-oriented constructions ${ }^{\mathbf{5 1}}$.

\section{Countermeasures and Advices}

Based on those thinking,we believe that the reasons of the dilemma between finding jobs for undergraduates and employment for employers ,of singular popularities for officials ,banking and state-owned enterprise are mainly unreasonable structure in running universities,irrational treatment in different industries ,and iffy training mode except the problem in employment education . What can we do to turn the tide ? Our countermeasures and advices are as follows:

\subsection{Countermeasure on Micro-system Level}

3.1.1 To reform salary system . To change traditional employment concept by adjusting salary treatment . The main basis is the contradiction between recruiting and interview . To increase absolute salaries of skilled jobs and decrease relatively salaries treatment of the officials , banking and state-owned enterprise . Of course, those adjustments are based on investigation and study .

3.1.2 To establish integrated modern occupation education system . That is to say occupational schools should include not only secondary vocational education and higher vocational educational 
education but undergraduate education and postgraduate education. education , college education, undergraduate education to postgraduate education (to enter universities by college entrance examination in spring or summer ), but to form their own system in higher vocational colleges (occupational colleges also have undergraduate education, as well as professional master education). To build a set of standard of modern occupation educational system and measures of evaluation, to give them political preference, to lead the occupational colleges we have now to refine (found undergraduate education and postgraduate education ) and to guide college and some universities, which totally have 845 , occupied about $74 \%$ of all that of China . Shandong has 46 , occupied $72 \%$ of 845 , to change to occupational colleges. At the same time, to try to approve the academic points of students who are in occupational colleges and encourage them to gain corresponding degree by proper text form, like double certificate examination in the grafting process assessment.

\section{2 advices on microscope}

3.2.1 To carry out " $2+1$ " mode for junior college students and " $3+1$ " for undergraduates. The " +1 " in mode means students use their last year in school to practice. And " 2 " means junior college students use first two tears to learn speculative knowledges. " 3 " means undergraduates use their three years to study speculative knowledges. Only when they study knowledges for $2 / 3$ of the time and practice $1 / 3$ of that, as well as military training ,entrance and graduation education , occupational guidance, labor and work-study program , social survey and so on, will they achieve the practical class requirements prescribed by ministry of education.

3.2.2 To cultivate higher vocational college students in general universities . Although colleges put vocational entrance and professional entrance together nearly two years (before they were divided into two parts) and these students have near results in college entrance examination , they are admitted by schools in different nature and accept different cultivative mode. They get equal specialist qualifications but have widely separated professional qualities. According to our study, we find that most general universities use mode that cultivate undergraduates to train college students, resulting in the college students theoretical level is not high and manipulative abilities is very low . "Not a world without touching the ground". They are not only poor in finding a job but easy to be fired. In conclusion, the mode that cultivate junior college students should close to that of higher vocational school .

\section{The Key Work}

To achieve the Higher Vocational Training Pattern, some important measures must be done firstly:

4.1 The formulation and implementation of the teaching standards of correlated curriculum practice, including teaching contents and methods, the methods and standards of evaluating students and teachers ,and when and where they finished.

4.2 Textbooks construction should embody the contents and methods of the course teaching practice. At present, the existing partial curriculum practice and training materials are separated from the textbooks, which do not reach the effect of less teaching and more practice, in addition, also increase the economic burden for students.

4.3 The construction and training of the teacher troop. Strengthen the construction of "the double quality" teachers, and actively push the tutorial system. Each class should be supervised by one professional teacher who works as a tutor, and hands over traditional role of the head teacher to the counselor, which can make tutors have more free time to carry out the training pattern of " $2+1$ ", and to instruct students' professional studying and teaching practice, including double card learning, optional curriculum, plans of personal growth, social practice, position internship, graduation internship and so on.

4.4 Pay more attention on construction of the fieldwork base and explore the ways of deep cooperation with school-run enterprises. Focus more on the deep cooperation with school-run enterprises, such as the win-win "order-form cultivation”, some win-win special classes, and the win-win construction of training center for school-run enterprises.

4.5 Organize the course internship of first two years, the fifth term of post- fixing practice, and 
the sixth term of graduation internship. This work is based on the construction of the fieldwork base and the deep cooperation with school-enterprise.

4.6 Strengthen the construction of the school training platform (center or base), and the laboratory construction different from the traditional ones. So far, with the center and local financial support, traditional laboratory construction has satisfied the need of confirmative and simulative relationship for students, but has long way to achieve the construction of the training platform (center or base). For one thing, school need pay more attention on the construction; for another, it can be achieved by strengthening the cooperation with school-run enterprises.

\section{References}

[1] Several opinions of the Ministry of education and other departments on Further Strengthening the work of university education practice (Teaching of Ideological and political No. [2012]1) http://www.moe.edu.cn/publicfiles/business/htmlfiles/moe/s6870/201209/xxgk_142870.html [2] Li Keqiang chaired a State Council executive meeting, the deployment of speeding up the development of modern occupation education.

[3] Applied University: Development Direction of teaching undergraduate colleges http://www.huaue.com/news/200562090604.htm

[4] with[3]

[5] The transformation of the university management of Shandong as the "classification running classification management" mode http://www.jyb.cn/high/gdjyxw/201211/t20121106_516701.html

[6] List of higher school in 2013 with a general higher education entrance qualification 